\title{
A Martin Scorsese Feature Film Chronology
}

\author{
Who's That Knocking at My Door (1967) \\ Boxcar Bertha (1972) \\ Mean Streets (1973) \\ Alice Doesn't Live Here Anymore (1974) \\ Taxi Driver (1976) \\ New York, New York (1977) \\ Raging Bull (1980) \\ The King of Comedy (1983) \\ After Hours (1985) \\ The Color of Money (1986) \\ The Last Temptation of Christ (1988) \\ New York Stories ("Life Lessons" segment, 1989) \\ Goodfellas (1990) \\ Cape Fear (1991) \\ The Age of Innocence (1993) \\ Casino (1995) \\ Kundun (1997) \\ Bringing Out the Dead (1999) \\ Gangs of New York (2002) \\ The Aviator (2004) \\ The Departed (2006)
}


xvi - A Martin Scorsese Feature Film Chronology

Shutter Island (2010)

Hugo (201 I)

The Wolf of Wall Street (2013)

Silence (2016)

The Irishman (2019) 
Martin Scorsese and the American Dream 


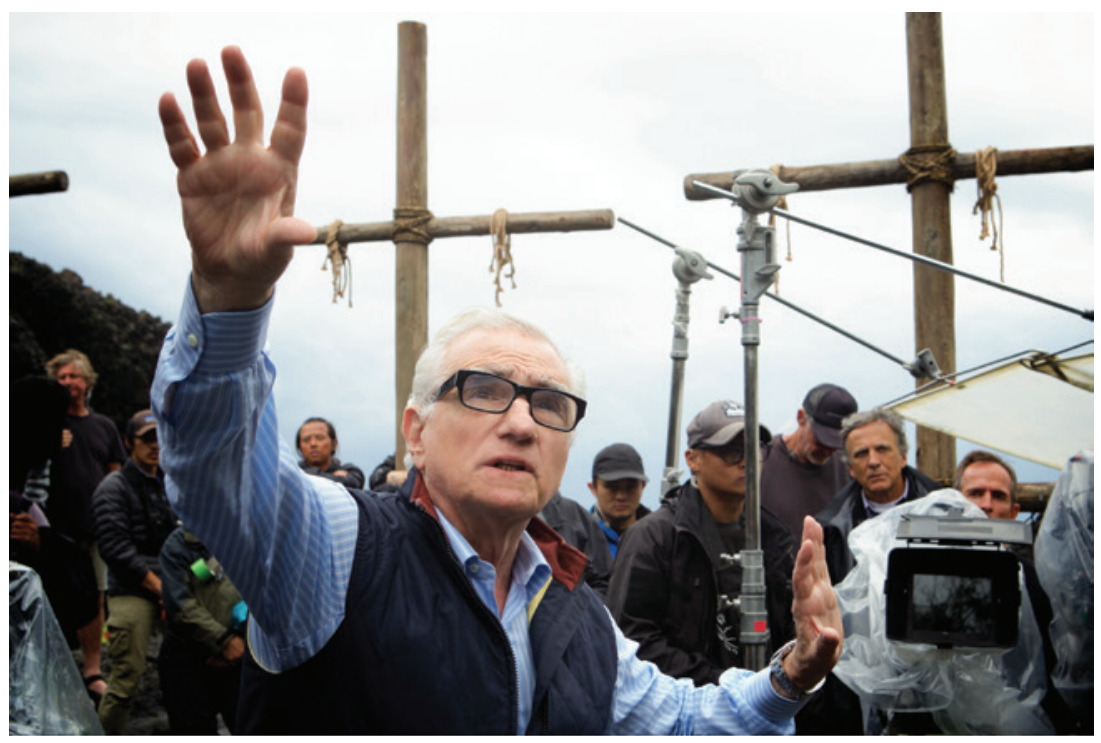

CROSS PURPOSES: Scorsese on the set of his 2016 film Silence, based on the novel by Japanese writer Shūsaku Endō. Scorsese's entire career has been marked by an effort to grapple with the tension between his parochial upbringing and the global reach of his talents and ambitions. In many of his films, characters navigate between tribal and wider worlds in the pursuit of their aspirations. (Photofest) 